\title{
Topology of Low Noise Polygonal Slotless BLDC Motor Designed for High Volume Production
}

\author{
Valentin Préault* Non-member, Christophe Espanet* Non-member
}

(Manuscript received January 25, 2021, revised May 28, 2021)

\begin{abstract}
Noise is a key asset in air management applications. The use of slotless motors is an effective solution to mitigate the noise due to magnetic forces on teeth. In this paper, we propose a topology of slotless motors with toroidal winding that enables noise reduction and that simplifies the manufacturing process. With prototypes of this technology, we have been able to reduce the acoustic noise by $5 \mathrm{~dB}$ in comparison with existing classical slotted motors.
\end{abstract}

Keywords: Slotless motors, toroidal winding, less noise, mass production design.

\section{Introduction}

Slotless motors with toroidal winding are of good interest for air management applications since those applications request low noise. Especially for electric vehicles and battery cooling, but also medical applications such as continuous positive airway pressure machines or home appliance applications such has portative vacuum cleaners, hair dryers... Due to the large airgap and the annular shape of the stator, magnetic efforts acting on the magnetic circuit and variation of those efforts are lower with slotless machines structures than with classical slotted motors. This feature makes slotless machine an interesting topology for silent applications. Despite this asset, slotless machines are not always preferred due to the complexity of manufacturing ${ }^{(2)}$. Winding issues can be even more complex for toroidal machines ${ }^{(3)}$. A solution for radial motors could be to use PCB windings ${ }^{(4)}$, but even if the motor constant (torque per square of stator copper losses) of such motor can be optimized in comparison with classical winding, the printed copper price still remains costlier than the drawn copper. These reasons explain why slotless topologies are not often chosen for mass production like for automotive applications. In order to take advantage of slotless machines without being hampered for large volume production, an original topology using toroidal winding and corresponding manufacturing process have been introduced. It is detailed in section 2 and then a comparison of experimental results with the proposed topology and classical slotted motors is presented in section 3 .

\section{Description of the polygonal topology}

In order to simplify the manufacturing, a patented technology of slotless toroidal machine has been developed ${ }^{(5)}$. The patent describes a simplified manner to realize the toroidal

\footnotetext{
${ }^{*}$ Moving Magnet Technologies, 1 Rue Christiaan Huygens, 25000 Besançon, France.
}

This paper is based on Reference ${ }^{(1)}$, which published in the 23rd International Conference on Electrical Machines and Systems (2020) @2020 IEEJ. stator. The stator consists of straight strips with several cuts (Fig. 1a). As shown in Fig. 1, that allows to fold it (Fig. 1b) to form a polygonal torus (Fig. 1c). Thanks to the straight shape of the stator, lamination stack cutting losses can be reduced.
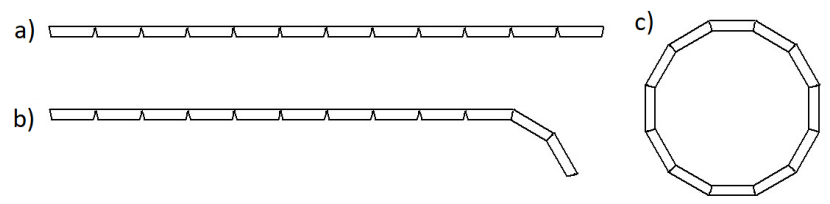

Fig. 1: Multi-segments folding stator principle,a) electrical steel sheet shape, b) partially folded stator, c) folded stator

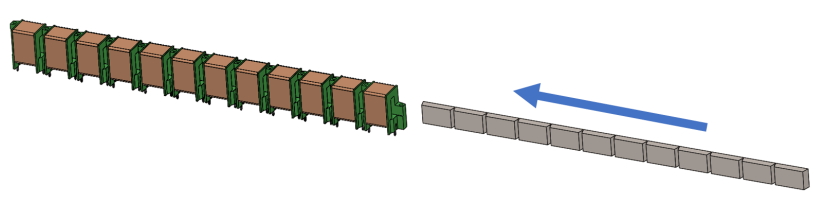

Fig. 2: Easy winding bobbins and stator insertion

Prior to fold the stator, the lamination stack is inserted into the bobbins (Fig. 2). The bobbins can be wounded before or after the insertion. If the lamination stack is wounded after insertion, bobbins can be made of two parts clamped on the lamination stack to compress lamination stack during wounding. The straight shape of the stator allows to wound every coil with the same wire. That strongly simplifies the manufacturing process. Furthermore, the rectangular section of the coils enables to reach a high filling factor. To increase magnetic flux of toroidal motors, it is possible to use magnets facing stator on several sides. In Fig. 3, the configuration with 2 faces rotor is presented. It is even possible to place magnets on upper or lower face (Fig. 3b) to maximize flux and torque of the motor. To increase the magnet flux through the stator without saturating it, it will need to be thicker. Thus, 


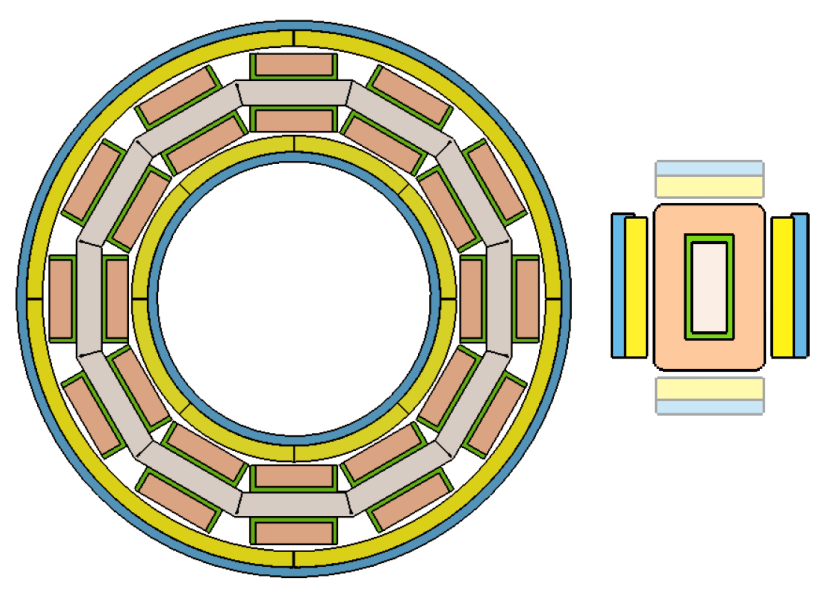

(a) transverse cut view

(b) radial cut view

Fig. 3: Toroidal motor with internal and external rotors

end winding will be longer, that will increase electrical resistance. So, it is not always interesting to have more or stronger magnets. Such topologies are well suited for hard ferrite or plastic bonded magnets.

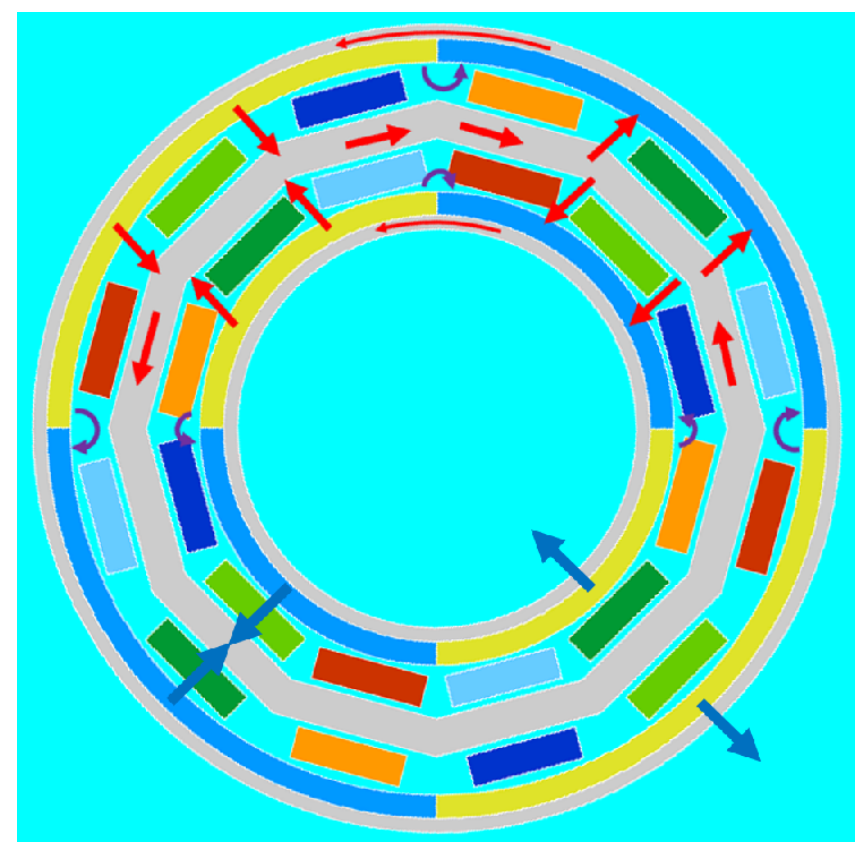

Fig. 4: FEM model of the proposed topology showing magnets flux path on half of the motor

Topology with 12 slots and 2 poles pairs, shown in Fig. 4, appears to be the best in terms of performances. This topology offers a good torque coefficient with low winding harmonics. Dodecagon is a good discretization in terms of manufacturing. It allows to have a good filling factor with low additional airgaps, and avoid losing too much space with bobbins. The magnets can have a radial or diametrical magnetization. Innner and outer rotor are synchronous. Both rotor magnetization flow toward or outward the stator on the same portion (Fig. 4 blue arrows). Due to the large airgap of slotless toroidal machines, a portion of magnet flux (Fig. 4 red arrows)is directly flowing from one magnet to its neigh- bor on each transition (Fig. 4 purple arrows) without flowing through the coils. An angle of 2 to $4^{\circ}$ can be saved on each magnet ends without depreciating motor performances. So, topologies with higher polarities are not interesting. Lower number of poles is not suitable for blower application with rotation speed below $15 \mathrm{krpm}$ because torque constant will be too low. When designing a motor in a given space (fixed outer diameter) one can see that increasing thickness of coils to reduce losses will increases the airgap and reduce the diameter of the stator, so torque constant. Thickness of the stator reduce iron losses but increase end winding resistance and reduce stator diameter and copper section. Thickness of the magnets can increase torque constant, but reduce copper section and stator diameter. So, a compromise has to be determined between all these parameters during design phase to get the best sizing. This technology can be used with the inner or outer rotor alone, but get better performances with both. As other outer rotor technologies, it offers very good axial compactness. Bearing can be fitted inside the inner rotor. Thus, motors designed with this technology has flat shape.

\section{Prototypes and comparison with existing auto- motiv HVAC blower motors}

Many automotive HVAC blower motors are nowadays BLDC motors. They are often made of an external rotor with ferrite magnets glued on a stamped bell and wounded teeth with poles shoes. Such topologies offer good compromise in terms of efficiency, noise, compactness and cost. So the 42W (3400rpm / 0.12N.m) motor in Figure 5, with 9 slots and 3 poles pairs. It is mounted on an aluminum flange to cool both motor and electronic (not visible in the picture). All coils are wounded with the same wire to reduce connections cost and electric resistance. Magnets tiles are shaped to reduce cogging torque.

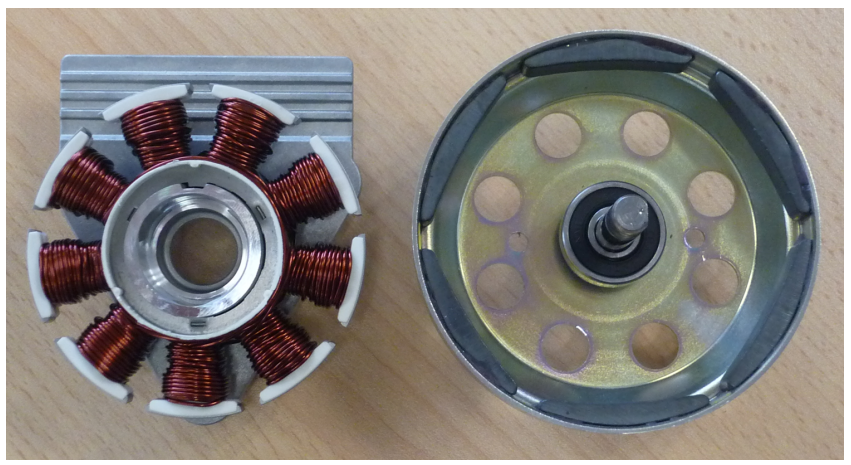

Fig. 5: 42W outer rotor slotted blower motor

The proposed technology has been compared to this $42 \mathrm{~W}$ slotted external rotor motor. A motor has been designed to fit within the same space and prototyped (Fig. 6). Characteristics of both motors are compared in Tab. 1. One can see that the torque constant of the polygonal motor is much smaller than the slotted motor. Moreover, terminal resistance is higher. That means that this motor will require more current for the same torque and will have more copper losses. But it will be able to run faster with the same supply voltage. So output power will be the same, but at different working 


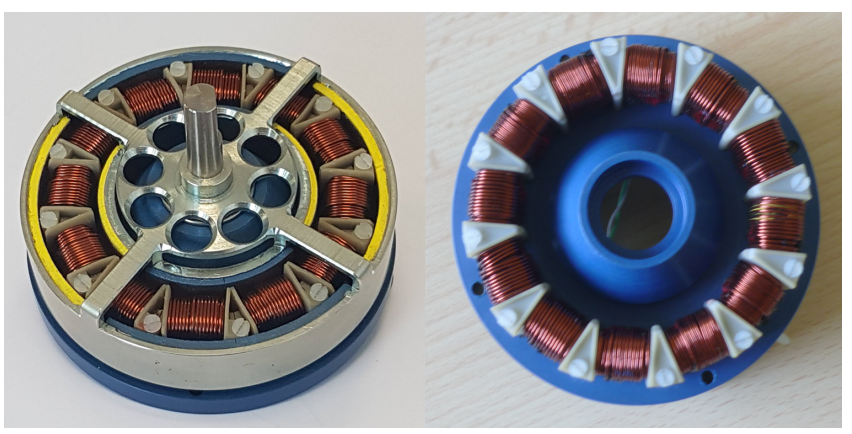

Fig. 6: 42W polygonal slotless prototype motor

point. This can be observed in Fig. 7 and Fig. 8. Those figures present the maximum efficiency reached by both motors for a given torque vs speed curve. These curves have been plotted with sinusoidal driving mode without space vector modulation with $12 \mathrm{~V}$ and $7 \mathrm{~A} / \mathrm{mm}^{2}$ RMS in coils limitations. This limitation is usually chosen for blower motor with active cooling by air flow. Since both motor have the same size, it is fare to compare them with the same current density witch represent the same amount of copper losses per copper unit. Slotted motor can reach higher torque with the same current limit and its maximal efficiency is slightly higher. But polygonal motor can reach higher speed with the same voltage $(12 \mathrm{~V})$. The best efficiency zone is not located at the same position for both motors. It means that the proposed technology, with same dimensions as external slotted motors, is not well suitable for high torque working point but rather with lower torque and higher speed. Due to the large airgap, to get a sufficient torque constant with the same magnet remanence, the polygonal motors have two rotors. Thus, polygonal motor is a little heavier.

Table 1: 42W motors comparison

\begin{tabular}{|l|c|c|}
\hline Property & $\begin{array}{c}\text { Reference technology } \\
\text { (benchmark) }\end{array}$ & Proposed technology \\
\hline Size & $\varnothing 84 \mathrm{~mm} \mathrm{~h} 25 \mathrm{~mm}$ & $\varnothing 86 \mathrm{~mm} \mathrm{~h} \mathrm{24mm}$ \\
\hline Weight & $428 \mathrm{~g}$ & $446 \mathrm{~g}$ \\
\hline Polarity & $6 \mathrm{poles}$ & $4 \mathrm{poles}$ \\
\hline Remanence & $0.37 \mathrm{~T}$ & $0.37 \mathrm{~T}$ \\
\hline Terminal torque constant & $21.8 \mathrm{mN} \cdot \mathrm{m} / \mathrm{A}$ & $15.6 \mathrm{mN} . \mathrm{m} / \mathrm{A}$ \\
\hline Terminal resistance & $140 \mathrm{~m} \Omega$ & $200 \mathrm{~m} \Omega$ \\
\hline Terminal inductance & $440 \mu \mathrm{H}$ & $400 \mu \mathrm{H}$ \\
\hline Max efficiency & $81 \%$ & $80 \%$ \\
\hline No load noise $(5 \mathrm{krpm})$ & $47 \mathrm{~dB}$ & $42 \mathrm{~dB}$ \\
\hline
\end{tabular}

The noise of both motors has been measured with no load. Motors have been driven with sensorless sinusoidal controller from 600 to $8000 \mathrm{rpm}$. Noise has been measured with a microphone, $1 \mathrm{~m}$ ahead rotor side. One can see in Fig. 9 that the slotted motor makes less noise at low speed, while the polygonal slotless motor makes less noise at high speed, even if it is a prototype. Despite it makes less noise than the slotted motor at high speed, polygonal slotless motor can still be improved. Due to its flattened shape the rotor has not been very well balanced. Thus, the first mechanical order makes noise. It can be seen in the bottom of Fig. 11. Both motors have resonant frequencies. This is the main source of noise of polygonal slotless motor at low speed (@ 2,1 kHz). Then for both motors, the main source of noise depends on mo-

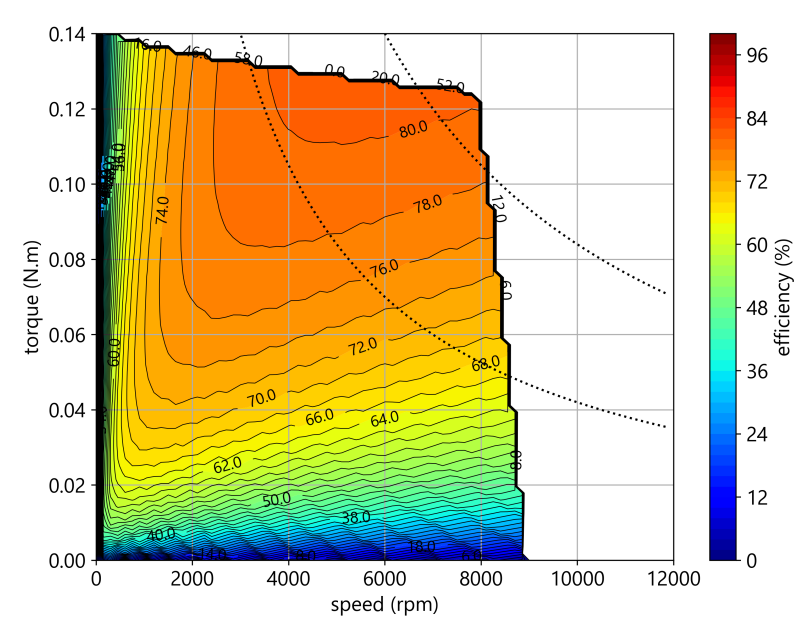

Fig. 7: 42W outer rotor slotted motor efficiency map computed with sinusoidal driving mode (without space vector modulation) with $12 \mathrm{~V}$ and $7 \mathrm{~A} / \mathrm{mm}^{2} \mathrm{RMS}$ in coils limitations. Dashed lines : isopower $42 \mathrm{~W}$ and $84 \mathrm{~W}$.

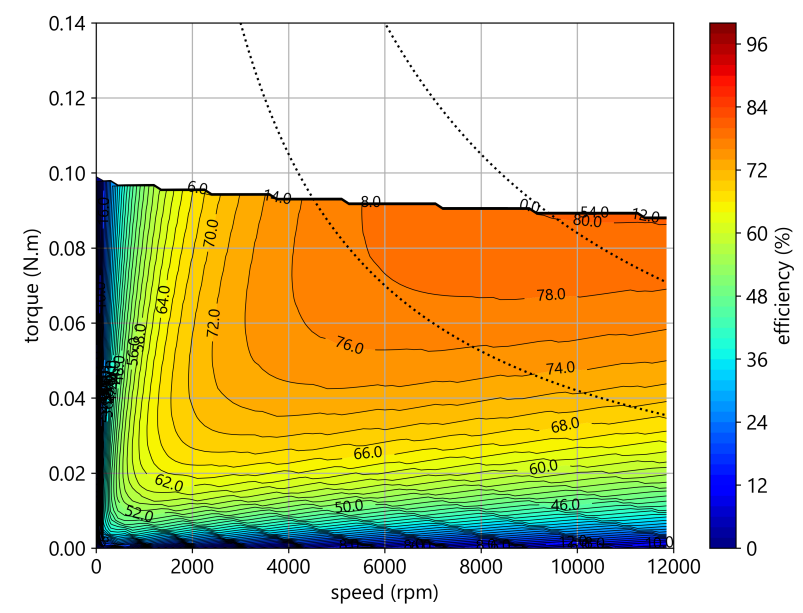

Fig. 8: $42 \mathrm{~W}$ polygonal slotless motor efficiency map computed with sinusoidal driving mode (without space vector modulation) with $12 \mathrm{~V}$ and $7 \mathrm{~A} / \mathrm{mm}^{2} \mathrm{RMS}$ in coils limitations. Dashed lines : isopower $42 \mathrm{~W}$ and $84 \mathrm{~W}$.

tor speed. One can also observe in Fig. 10 and 11 that both motors have low number of tonal noises. These tonal noises have low tone to noise ratio ${ }^{(6)}$. Polygonal slotless machines are thus good candidates for low noise applications.

Slotless toroidal motors, with perfectly circular stators, benefit from constant airgap to avoid any parasitic magnetic force. Thus, those motors didn't have any cogging torque nor reluctance torque. The proposed technology is slotless toroidal but with a polygonal stator. Thus, cogging torque and noise sources may come from the polygonal shape of the stator. Attention has to be paid during design and assembly. The lamination stack has to be at the right position (circularity) and well maintained within the bobbins. If the lamination stack is inserted after wounding, the backlash between stator bobbins must be compensated in order to place the iron at the right position. Special care has to be paid on the shape of each cuts in the stator strips to get a proper contact between each segment (see Fig. 12 - left). In order to prevent un- 


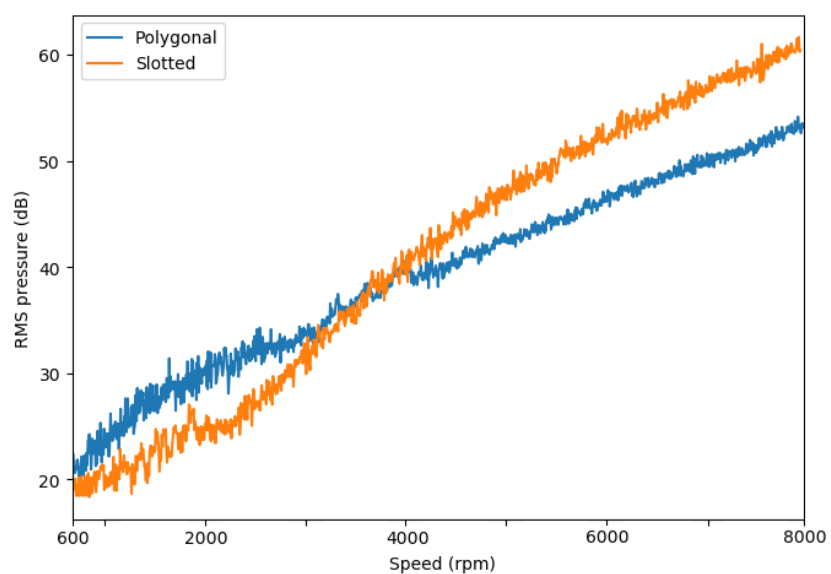

Fig. 9: No load noise Vs speed comparison between motors

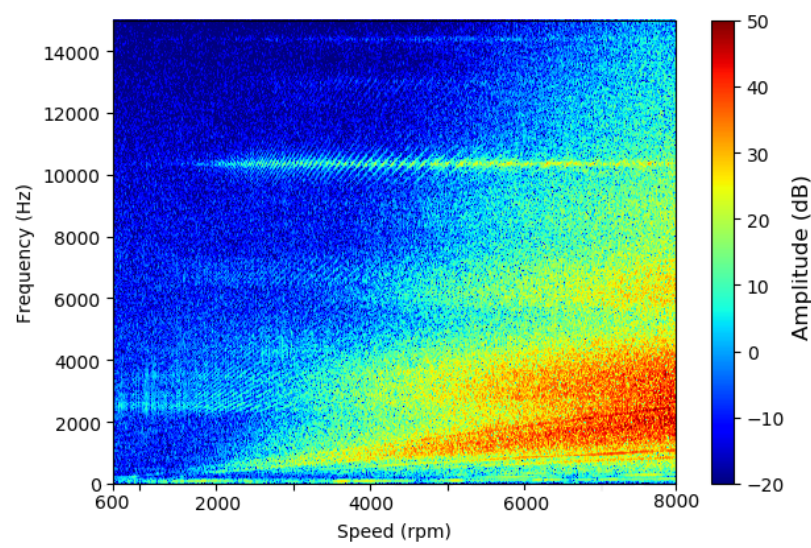

Fig. 10: 42W outer rotor slotted motor spectrogram (1m)

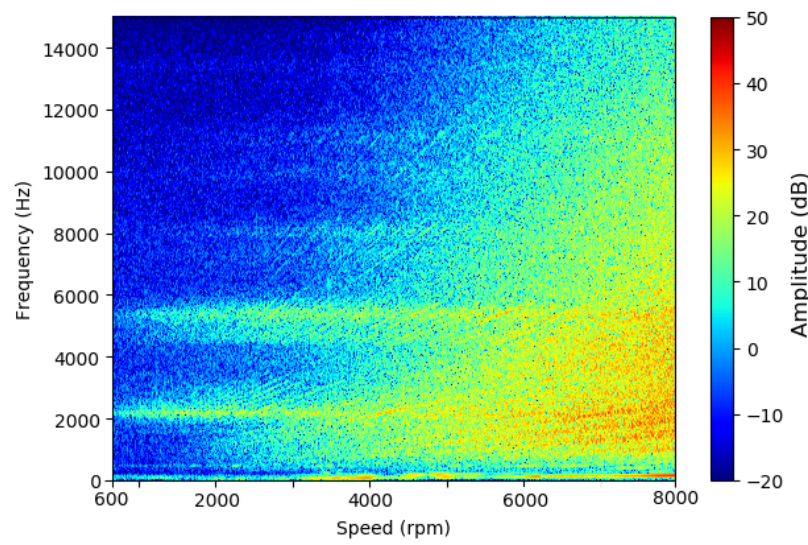

Fig. 11: 42W polygonal slotless motor spectrogram (1m)

wanted effects from these airgaps, other asymmetric shapes can be used and alternated, to avoid alignment of these airgaps (Fig. 12 - right).

\section{Additional prototypes}

This technology has been challenged on other blower applications with different power levels. First compared to a 250W (3500rpm / 0.7N.m) outer rotor motor, designed with twelves teeth and four poles pairs (Fig. 13). The prototype can be seen in Fig. 14. It is the same topology than the first prototype with twelves coils and two poles pairs. It has been designed for hard ferrite magnets. Characteristics of

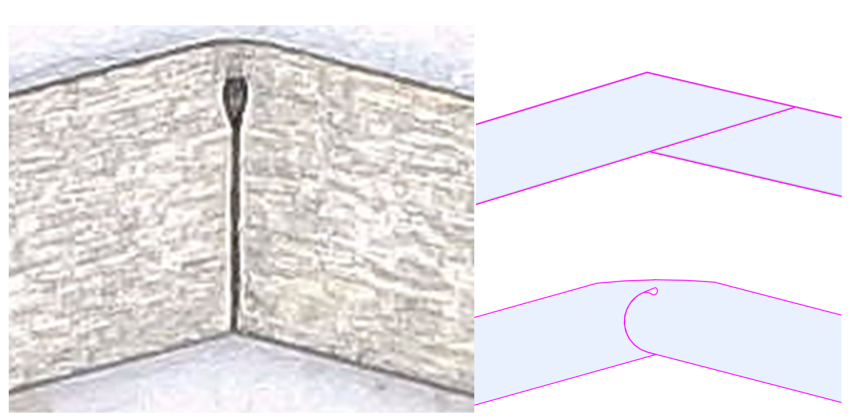

Fig. 12: Stator slots closing

both motors are compared in Tab. 2. Same conclusions as previous study can be drawn. In terms of efficiency, this technology is better suited for higher speed and lower torque but makes less noise at high speed. With such size $(\varnothing 100 \mathrm{~mm}$ h30mm) of motors, the technology presented in this article makes sense. The winding is easy and the size of the parts makes them easy to handle.

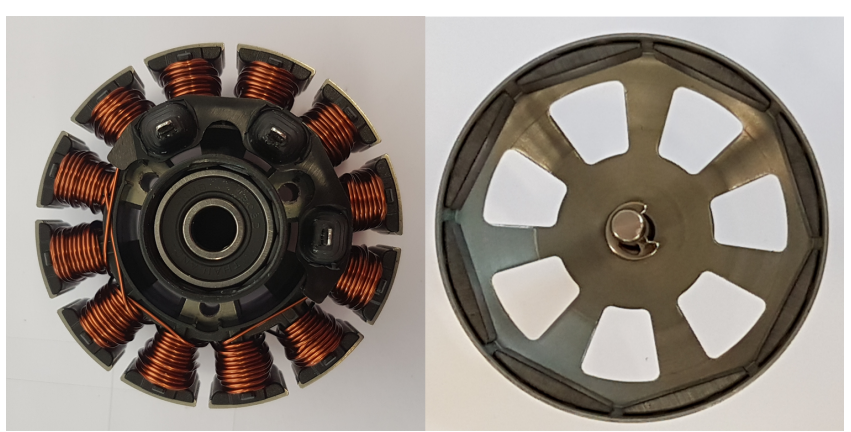

Fig. 13: 250W outer rotor blower motor

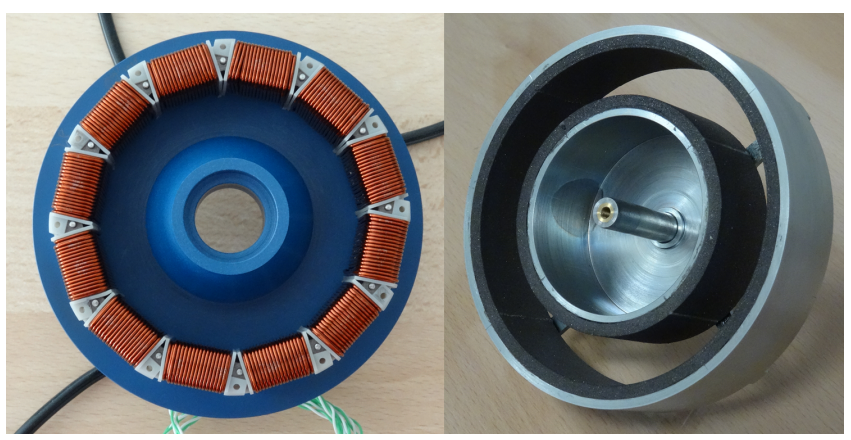

Fig. 14: 250W Polygonal slotless prototype

Forces acting on each teeth or segments have been computed for both motors during one electric period. Forces acting on slotted motor teeth are plotted in Fig. 15 and forces acting on polygonal motor segments are plotted in Fig. 16. Forces have been computed using Maxwell stress tensor. One can see that the forces acting on the outer rotor motor teeth are much higher than polygonal motor segments. This is due to the slots of the stator modifying the reluctance along rotor rotation. Thus, the force acting on each tooth is much higher. The magnetic forces acting on each segments of polygonal motor are small due to the compensation of both inner and outer rotors. The torque acting on slotless stator is due to 
Topology of Low Noise Polygonal Slotless BLDC Motor Designed for High Volume Production (Valentin Préault et al.)

Table 2: 250W motors comparison

\begin{tabular}{|l|c|c|}
\hline Property & $\begin{array}{c}\text { Reference technology } \\
\text { (benchmark) }\end{array}$ & Proposed technology \\
\hline Size & $\varnothing 89 \mathrm{~mm} \mathrm{~h} 50 \mathrm{~mm}$ & $\varnothing 98 \mathrm{~mm} \mathrm{~h} 31 \mathrm{~mm}$ \\
\hline Weight & $840 \mathrm{~g}$ & $910 \mathrm{~g}$ \\
\hline Polarity & $8 \mathrm{poles}$ & $4 \mathrm{poles}$ \\
\hline Remanence & $0.43 \mathrm{~T}$ & $0.43 \mathrm{~T}$ \\
\hline Terminal torque constant & $19 \mathrm{mN} \cdot \mathrm{m} / \mathrm{A}$ & $19 \mathrm{mN} . \mathrm{m} / \mathrm{A}$ \\
\hline Terminal resistance & $45.7 \mathrm{~m} \Omega$ & $68 \mathrm{~m} \Omega$ \\
\hline Terminal inductance & $71 \mu \mathrm{H}$ & $85 \mu \mathrm{H}$ \\
\hline Max efficiency & $78 \%$ & $77 \%$ \\
& $(4 \mathrm{krpm}, 0.6 \mathrm{~N} . \mathrm{m})$ & $(6 \mathrm{krpm}, 0.4 \mathrm{~N} . \mathrm{m})$ \\
\hline No load noise $(3.5 \mathrm{krpm})$ & $41 \mathrm{~dB}$ & $35 \mathrm{~dB}$ \\
\hline
\end{tabular}

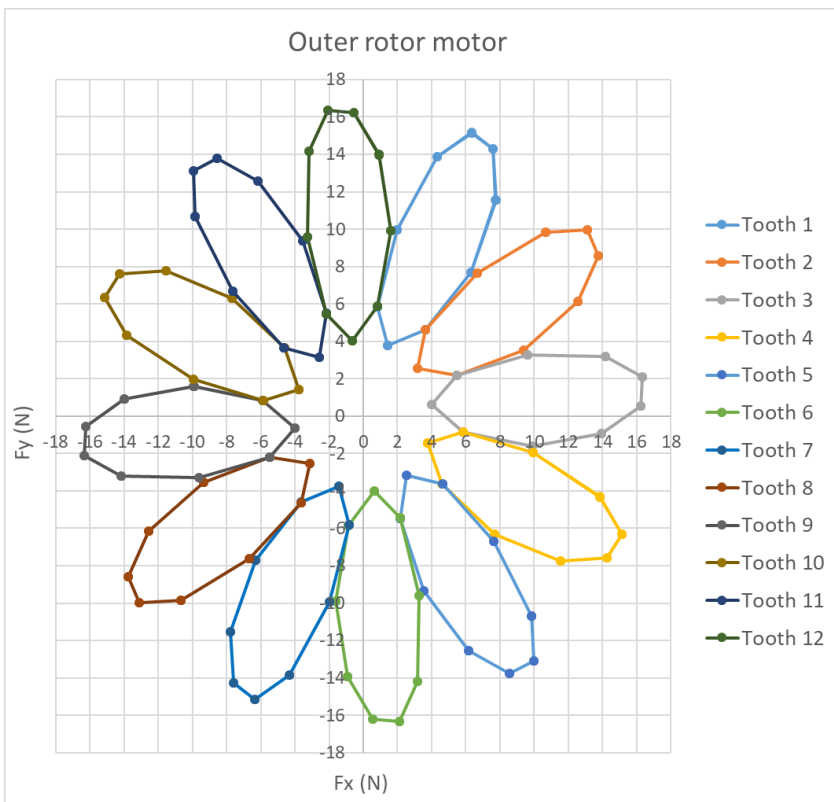

Fig. 15: Forces on slotted motor teeth during one electric period, computations with current

Laplace force. It is supported by copper wires nor stator iron. Is is obvious that noise is not only related to magnetic forces. Other reasons, that can be among others mechanical or electronic driving solution, may be strong sources of noise. But the noise is due to the response of a structure to vibrations. Reducing forces variations on motor structure goes in the right direction. Lower magnetic forces on stator iron can explain reduction of the noise of the motor.

Second, on a small vehicle with a 20W (10000rpm / 20mN.m) blower motor. The motor can be seen in Fig. 17. This prototype has been designed with plasto-neodymium magnets. The motor is $14 \mathrm{~mm}$ high and its diameter is $45 \mathrm{~mm}$. It allowed us to observe than the compactness is very good and the technology make sense also for such small motors. It wheight $90 \mathrm{~g}$ and reach $80 \%$ efficiency at working point. The noise emitted by this motor has not been measured yet.

\section{Conclusion}

The motor technology presented here is based on slotless toroidal machines. Those machines have large and constant airgap so that they are good candidates for low noise applications. Indeed, this configuration leads to small magnetic forces, in terms of mean value and amplitude of variations. For the same size, we have shown that best efficiency zone of

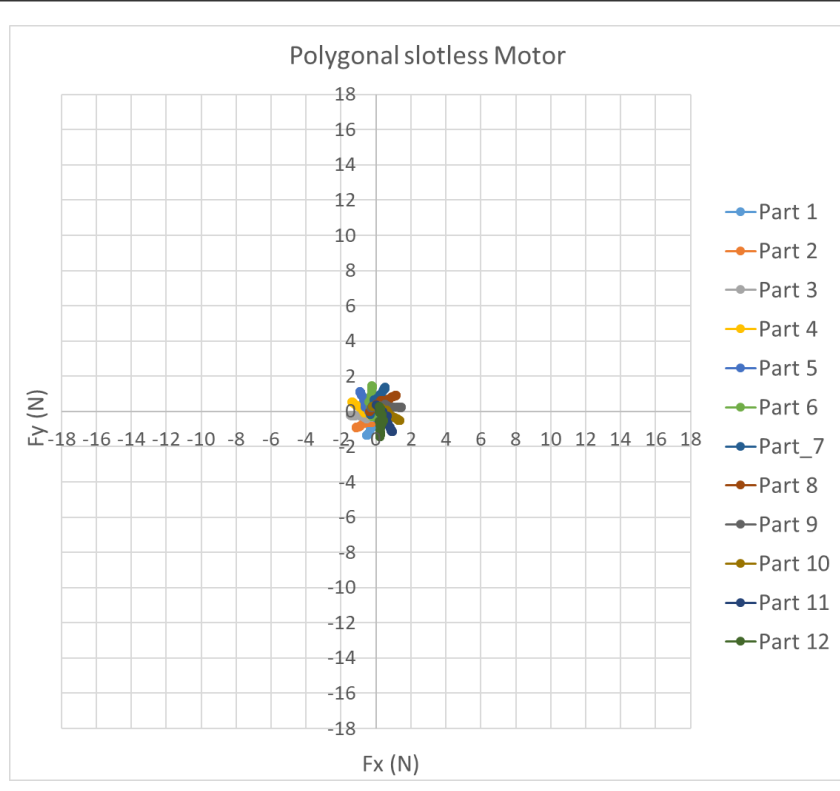

Fig. 16: Forces on polygonal slotless motor segments during one electric period, computations with current

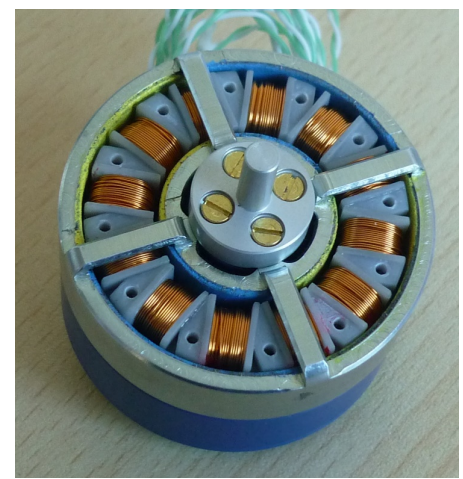

Fig. 17: 20W Polygonal slotless prototype

such topologies is located at higher speed and lower torque than classical slotted machines. But such topologies are difficult to produce with high volumes capabilities. The proposed technology solves this issue. It allows an easy winding and manufacturing. Even if the stator has to be folded on several segments, and has not a perfect circular shape, prototypes show that this technology makes low noise. Finally, this technology is a good compromise in terms of size, efficiency, noise emission, cost for mass production in range of 20 to $250 \mathrm{~W}$ and for rotational speed preferentially higher than $3000 \mathrm{rpm}$.

\section{References}

( 1 ) V. Préault and C. Espanet "A topology of low noise polygonal slotless BLDC motor designed for high volume production," 23rd International Conference on Electrical Machines and Systems (ICEMS 2020), 2020.

( 2 ) P. Ragot, M. Markovic and Y. Perriard, "Analytical Determination of the Phase Inductances for a Brushless DC Motor with Faulhaber Winding," 2007 IEEE Industry Applications Annual Meeting, New Orleans, LA, 2007, pp. 1538-1543, doi: 10.1109/07IAS.2007.238.

( 3 ) H. Lee, E. Lee, G. Lee and S. Kwon, "Evaluation of Slotless Permanent Synchronous Motor with Toroidal Winding," 2019 IEEE Energy Conversion Congress and Exposition (ECCE), Baltimore, MD, USA, 2019, pp. 17351738 . 
( 4 ) B. Dehez, F. Baudart and Y. Perriard, "Analysis of a new topology of flexible PCB winding for slotless BLDC machines," 2014 International Conference on Electrical Machines (ICEM), Berlin, 2014, pp. 1963-1969, doi: 10.1109/ICELMACH.2014.6960453.

( 5 ) G. Andrieux, A. Hyppias and L. Herbein, "Machine Electrique Toroidale Polyphasee" FR3072517.

( 6 ) ECMA-74 17th Edition / Measurement of Airborne Noise Emitted by Information Technology and Telecommunications Equipment

Valentin Préault (Non-member) He received a Ph.D. degree in

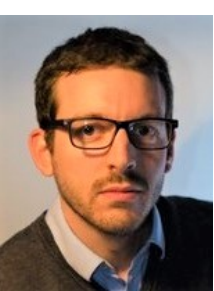
physics from Université Paris Saclay, France, in 2013, and is presently deputy manager of the drive motor innovation unit of Moving Magnet Technology S.A. (Besançon, France). He is working on reducing noise of motors and improvement of motors manufacturing.

Christophe Espanet (Non-member) $\mathrm{He}$ received a $\mathrm{Ph} . \mathrm{D}$. degree in electrical engineering from the University of Franche-Comte, France, in 1999. His doctoral research was dealing with the optimal design of PM BLDC in-wheel motors. From 1999 to 2015, he has been assistant professor and full professor with the University of Franche-Comte, France. He is now scientific director of Sonceboz Group and he is leading a research teams which are developing new mechatronics solutions. 